\title{
IMPLEMENTASI GOOD GOVERNANCE SEBAGAI UPAYA PENCEGAHAN PENYAKIT BIROKRASI DALAM PELAYANAN PUBLIK (STUDI KASUS KASUS PELAYANAN ADMINISTRASI KEPENDUDUKAN DI KANTOR KECAMATAN MEDAN HELVETIA
}

Oleh:

Pangeran Teguh Anugrah ${ }^{1)}$

Abdul Kadir ${ }^{2)}$

Pin Pin $^{3)}$

Universitas Darma Agung, Medan ${ }^{1,2,3)}$

E-mail:

silalahi.pangeran@gmail.com ${ }^{1)}$

abdulkadir794@gmail.com $^{2}$ )

drpinpin62@gmail.com $^{3)}$

\begin{abstract}
District is part of the government organization that is closest to dealing directly with the community and spearheading the success of regional development, especially in Medan, where the District will be seen directly in planning and controlling development and services, and a reflection of good governance in Medan. The objectives of this study are as follows: (i) to describe the Good Governance implementation in the District, especially in the District of Medan Helvetia, (ii) to analyze the factors that support and inhibit the implementation in the District, especially in the District of Medan Helvetia.The form of descriptive research using a qualitative approach, this research was conducted in the District of Medan Helvetia. The informants consisted of key informants, namely the Head of District and their apparatus as many as 4 people who were determined purposively and the Main informant namely the community who were taken accidentally as many as 20 people at the time of the study. Primary data comes from interviews and secondary data from literature studies and other written documents. After the data and information needed has been collected, the researcher then sifts through the data and information into the research indicators that have been determined. After the data and information are grouped, the researcher then presents the data and analyzes the data qualitatively.Research Results: The good governance implementation in Medan Helvetia District Office refers to the Decree of the District of Medan Helvetia number 138/19-17/SKMH/IX/2015 on Standard Operating Procedures (SOP) in Medan Helvetia District Environment. In general, the implementation analysis as follows: (i) Standards and Policy Objectives: public servants have attempted to achieve the public service goals they have set, (ii) Resources: human resources and support resources or facilities, researchers see still shortcomings, (iii) Inter-Organizational Relations: inter-organizational relationships implemented in Medan Helvetia District are good, (iv) Characteristics of the Implementing Agent: the characteristics of the existing implementing agent can already be applied by the implementor of public services in both the public service in Medan Helvetia district, (v) Social, Political, and Economic Conditions: on the variable social, economic and political conditions, the implementors of public services in providing public services do not discriminate between each other, (vi) Implementor Disposition: the attitude given by the implementor of public services is friendly and courteous when providing public services. Supporting factors are cooperation with stakeholders, commitment of the head district (Camat), and the economic potential of the region and opportunities of private CSR, while the Inhibitor Factors are Lack of community participation, lack of human resources apparatus, lack of funds and some damaged road and drainage infrastructure.
\end{abstract}

Keyword: Good Governance, Public Service, Public Administration

\section{ABSTRAK}


Kecamatan adalah salah satu bagian dari institusi pemerintah yang paling dekat dan berhubungan langsung dengan masyarakat serta menjadi ujung tombak keberhasilan pembangunan daerah khususnya Kota Medan dimana kecamatan akan terlihat langsung didalam perencanaan dan pengendalian pembangunan serta pelayanan, dan menjadi cerminan baik buruk yang nyata terhadap tata kelola pelayanan publik pemerintahan Kota Medan. Tujuan penelitian ini adalah sebagai berikut: (i) mendeskripsikan implementasi good governance di Kecamatan khususnya pada Kantor Kecamatan Medan Helvetia, (ii) menganalisis faktor-faktor yang menjadi pendukung dan penghambat implementasi good governance di Kecamatan khususnya pada Kantor Kecamatan Medan Helvetia. Bentuk penelitian deskriptif dengan menggunakan pendekatan kualitatif, penelitian ini dilakukan di Kantor Kecamatan Medan Helvetia. Informan terdiri dari informan kunci yakni Camat dan Perangkatnya sebanyak 4 orang yang ditetapkan secara Purposif dan informan Utama yakni masyarakat yang diambil secara acak sebanyak 20 orang pada saat penelitian. Data primer bersumber dari wawancara dan data sekunder berasal dari studi kepustakaan dan dokumen tertulis lainnya. Apabila data dan informasi yang diperlukan telah terkumpul, peneliti kemudian memisah-misahkan data dan informasi tersebut kedalam indikator-indikator penelitian yang telah ditentukan. Setelah data dan informasi tersebut dikelompokkan, peneliti kemudian melakukan penyajian data dan analisis data secara kualitatif. Hasil Penelitian: Implementasi good governance di Kantor Kecamatan Medan Helvetia mengacu pada Surat Keputusan Camat Medan Helvetia nomor 138/19-17/SK-MH/IX/2015 tentang Standar Operating Procedures (SOP) di Lingkungan Kecamatan Medan Helvetia. Secara umum analisis implementasinya adalah sebagai berikut: (i) Standar dan Sasaran Kebijakan: pelayan publik telah berusaha mencapai sasaran pelayanan publik yang telah mereka tetapkan, (ii) Sumber daya: sumber daya manusia dan sumber daya pendukung atau fasilitas, peneliti melihat masih adanya kekurangan, (iii) Hubungan Antar Organisasi: hubungan antar organisasi yang dilaksanakan di Kecamatan Medan Helvetia sudah baik, (iv) Karakteristik Agen Pelaksana: karakteristik agen pelaksana yang ada sudah dapat diterapkan oleh pelaksana pelayanan publik secara baik dalam memberikan pelayanan publik di Kecamatan Medan Helvetia, (v) Kondisi Sosial, Politik, dan Ekonomi: pada variable kondisi sosial, ekonomi dan politik,pelaksana pelayanan publik dalam memberikan pelayanan publik tidak membedabedakan antara satu sama lain, (vi) Disposisi Implementor: sikap yang diberikan oleh pelaksana pelayanan publik ramah dan sopan pada saat memberikan pelayanan publik. Faktorpendukung: adanyakerjasamadengan stakeholder, komitmen pimpinan (Camat), dan potensi ekonomi wilayah dan peluang dari CSR swasta, sedangkan Faktor Penghambat: Minimnya Partisipasi masyarakat, kurangnya SDM aparatur, minimnya dan adan sebagian infrastruktur jalan dan drainase yang rusak.

\section{Kata-kata Kunci: Implementasi, Good Governance, Pelayanan Publik, Admistrasi Kependudukan}

\section{PENDAHULUAN}

Kecamatan Medan Helvetia sebagai institusi yang memiliki fungsi dalam menyelenggarakan pelayanan administrasi publik khususnya yang berkaitan dengan perijinan dan penerbitan, Surat Keterangan Kematian,Kartu Keluarga,Surat Tanah/Ahli Waris, dan Kartu Tanda Penduduk, untuk dituntut bekerja secara efisien dan mampu secara cepat menjawab masukan, tuntutan masyarakat dan perubahan lingkungan dengan cara kerja yang lebih ramah dan berorientasi kepada masyarakat daripada berorientasi kepada pemimpin seperti yang terjadi selama ini dalam lingkungan birokrasi pelayanan publik.

Birokrasi dalam menyelenggarakan fungsi pemerintahan dan fungsi pembangunan (termasuk penyelenggaraan pelayanan publik) diberikan kesan adanya proses panjang dan sulit apabila masyarakat 
ingin menyelesaikan urusan yang berkaitan dengan pelayanan aparatur pemerintahan.

Birokrasi selalu menerima citra buruk yang merugikan bagi peningkatan birokrasi itu sendiri (khususnya dalam pelayanan publik).Birokrasi tidak mampu lagi memposisikan diri sebagai sebuah institusi yang mulia dan tidak tersentuh oleh kritik dari pihak eksternal birokrasi.Tuntutan masyarakat mengenai perlunya dilakukannya perbaikan kualitas pelayanan publik telah menjadi masukan publik sampai dengan saat ini.

Dalam keadaan yang demikian, maka kiprah birokrasi aparatur pemerintahan harus mampu berinovasi demi kepentingan bangsa dan negara dan agar mampu menyelenggarakan fungsinya dengan baik, birokrasi harus mampu berpegang teguh pada berbagai peraturan perundang - undangan yang berlaku. Berkaitan dengan pelayanan dan perwujudan kesejahteraan rakyat, birokrasi publik memberikan andil yang sangat relatif besar. Semua hal yang terdapat dalam cakupan penyelenggaraan pemerintahan tidak bisa lepas dari konteks public services dan public affairs. Barang dan jasa publik hendaknya dapat diatur secara efisien dan efektif, sedangkan konsekuensi pengaturan tersebut menjadi tanggung jawab birokrasi.

Berdasarkan dari penjelasan uraian sebelumnya, maka penulis tertarik untuk melakukan penelitian dengan judul "IMPLEMENTASI GOOD GOVERNANCE SEBAGAI UPAYA PENCEGAHAN PENYAKIT BIROKRASI DALAM PELAYANAN PUBLIK (STUDI KASUS PELAYANAN ADMINISTRASI KEPENDUDUKAN DI KANTOR KECAMATAN MEDAN HELVETIA)"

\section{TINJAUAN PUSTAKA}

Suatu proses pengambilan keputusan kebijakan publik dapat dianalogikan fungsi serta penggunaannya sama dengan fungsi organ otak didalam tubuh manusia, karena melalui medium ini, segala aktivitas kehidupan bernegara dan bermasyarakat mulai dilakukan oleh birokrasi.

Kebijakan publik itu sendiri merupakan titik awal pengoperasian fungsi program-program atau kegiatan-kegiatan yang dilaksanakan oleh pemerintah, masyarakat dan pihak swasta.

Jika ditarik secara terminologi, maka kebijakan publik berangkat dari dua suku kata yaitu kebijakan (policy) dan publik (public).

Kebijakan dapat di artikan sebagai suatu upaya pencapaian sebuah tujuan tertentu yang dapat dilakukan oleh seorang individu secara personal/pribadi maupun kegiatan yang dilakukan oleh beberapa/sekelompok orang.

Berarti usaha tadi yang dilakukan oleh individu atau kelompok dalam hal ini adalah pemerintah semuanya ditujukan untuk kepentingan orang banyak, umum atau masyarakat. Atau dalam pengertian lain, semua yang dilakukan oleh pemerintah pada hakekatnya adalah atas dasar kemauan, keinginan, kepentingan dan kehendak masyarakat, demi tercapainya masyarakat yang adil dan makmur.

Jadi, dapat disimpulkan bahwa implementasi merupakan suatu proses yang terus bergerak yang banyak melibatkan secara terus menerus usaha-usaha untuk mencari segala sesuatu yang akan dan dapat dilakukan. Implementasi juga dapat mengatur kegiatan-kegiatan yang menuju pada penempatan suatu program ke dalam tujuan kebijakan yang ingin dicapai.Implementasi kebijakan adalah segala rangkaian aktivitas setelah suatu kebijakanakan dirumuskan.

Apabila tidak ada suatu implementasi dalam perumusan kebijakan maka suatu kebijakan yang telah dirumuskan akan sia-sia belaka.

Pada Penelitian ini Peneliti akan menggunakan Teori Implementasi Kebijakan Donald Van Meter dan Carl Van Horn(1975) dalam meneliti dan membahas mengenai ImplementasiGood Governance Sebagai Upaya Pencegahan Penyakit Birokrasi 
Dalam Pelayanan Publik di Kantor Kecamatan Medan Helvetia dengan menggunakan variable Donald Van Meter dan Carl Van Horn(1975) (Dalam Subarsono, 2011: 90-92), yaitu adanya 1.) Standar dan Sasaran Kebijakan, 2.)Sumberdaya, 3.) Hubungan Antar Organisasi, 4.) Karakteristik Agen Pelaksana, 5.) Kondisi Sosial, Politik, dan Ekonomi, dan 6.) Disposisi Implementor demi tercapainya Tujuan Pelayanan Publik yang diinginkan masyarakat.

Produktivitas maupun efektivitas dan efesiensi organisasi Negara atau pemerintah amat tergantung pada Aparatur Negara yang ada didalamnya, karena merekalah yang akhirnya menjadi pelaksana pemerintahan dan pembangunan.

Kualitas pelayanan telah menjadi kunci yang paling menentukan dalam menjaga keberlangsungan suatu organisasi birokrasi pemerintah maupun organisasi perusahaan.Pelayanan yang bermutu atau tepat sasaran dan sesuai dengan kebutuhan para pengguna jasa-jasa publik terutama masyarakat yang sangat penting dalam upaya mewujudkan kepuasan para pengguna jasa publik tersebut.

Tentang kualitas pelayanan publik pada Kantor Kecamatan Medan Helvetia, masih ditemukan beberapa kekurangan atau kelemahan dalam pelayanan.

\section{METODEPELAKSANAAN}

Adapun jenis penelitian yang akan digunakan pada penelitian penulis adalah deskriptif dengan pendekatan kualitatif. Dengan metode penelitian deskriptif ini peneliti akan berusaha mendeskripsikan atau menggambarkan secara terperinci atau komprehensif tentang bagaimana Implementasi Good Governance Sebagai Upaya Pencegahan Penyakit Birokrasi Dalam Pelayanan Publik di Kantor Kecamatan Medan Helvetia yang menjadi cerminan baik bagi Pemerintahan Kota Medan, adapun dengan pemilihan rancangan deskriptif kualitatif, diharapkan penulis akan dapat melakukan pendekatan terhadap obyek-obyek penelitian dengan menggali informasi dalam proses wawancara. Melalui hasil observasi lapangan serta catatan pribadi, penulis senantiasa akan menginterpretasikan makna yang tersurat dan tersirat dari penjelasan yang diberikan informan.

\section{HASIL DANPEMBAHASAN}

Dalam memberikan pelayanan publik di Kecamatan Medan Helvetia, terdapat tiga seksi yang bertanggung jawab dalam memberikan pelayanan publik di Kecamatan Medan Helvetia. Tiga seksi tersebut adalah Seksi Tata Pemerintahan, Seksi Pemberdayaan Masyarakat dan Seksi Kesejahteraan Sosial.Dalam menjalankan tugasnya, ketiga seksi tersebut diberikan tugas dan tanggung jawab sesuai dengan bidangnya masing-masing. Tugas dan tanggung jawab dari ketiga seksi tersebut adalah Seksi Tata Pemerintahan yang mempunyai tugas dan tanggung jawab, yaitu: pengurusan surat-surat atau dokumen penting yang berfungsi sebagai alat dan dokumen legalitas dalam masyarakat. Seksi Pemberdayaan Masyarakat mempunyai tugas dan tanggung jawab, yaitu: pengurusan Surat Undangan Musrenbang. Dan Seksi Kesejahteraan Sosial mempunyai tugas dan tanggung jawab, yaitu: pengurusan Surat Keterangan Ahli Waris, Surat Dispensasi Nikah, dan Surat Keterangan Kurang Mampu. Dalam penelitian ini, peneliti akan melakukan penelitian mengenai ImplementasiGood Governance Sebagai Upaya Pencegahan Penyakit Birokrasi Dalam Pelayanan Publik di Kantor Kecamatan Medan Helvetia. Dalam mengumpulkan data yang diperlukan untuk menjawab permasalahan pada penelitian ini, penulis melakukan dengan empat tahapan.Pertama melakukan observasi ke lapangan untuk mengetahui secara langsung bagaimana keadaan penelitian yang sesungguhnya.Kedua peneliti melaksanakan penelitian dengan melakukan wawancara dengan informan.Ketiga, peneliti mengumpulkan dokumentasi untuk mendukung dari data yang didapat melalui 
hasil wawancara dan observasi.Dan keempat, peneliti melakukan proses pengambilan data-data yang dapat diartikan sebagai suatu teknik pengumpulan data-data yang bersifat menyatukan dari berbagai teknik pengumpulan data-data dan sumber datadata yang telah ada.

Hal yang pertama dilakukan oleh penulis adalah dengan melaksanakan wawancara dengan informan yang berhubungan dengan permasalahan utama pada penelitian ini.Dalam melaksanakan wawancara untuk mendapatkan data yang diperlukan untuk menjawab permasalahan dari penelitian ini, peneliti melakukan wawancara dengan informan yang berhubungan dengan permasalahan yang ada.Sesuai dengan metode penelitian, peneliti telah menetapkan 22 orang narasumber. Dua puluh dua informan tersebut merupakan orang-orang yang memiliki fungsi jabatan atau fungsi kedudukan tertentu didalam institusi kecamatan karena dianggap dapat menjawab dan memberikan ide pemikiran atau jalan keluar dari segala sesuatu yang menjadi permasalahan utama dari penelitian yaitu yang berhubungan dengan proses Implementasi Good Governance Sebagai Upaya Pencegahan Penyakit Birokrasi Dalam Pelayanan Publik khususnya dalam Bidang Tata Pemerintahan di Kecamatan Medan Helvetia.Pada pelaksanaan wawancara yang dilakukan oleh penulis, penulis melakukan wawancara dengan Camat Medan Helvetia yang terdiri dari 1 orang, Sekertaris Camat Medan Helvetia yang terdiri dari 1 orang, Kasubbag Umum yang terdiri dari 1 orang, Kasubbag Keuangan dan Program yang terdiri dari 1 orang,KasiTataPemerintahanyangterdirid arilorang,PegawaidiKecamatan Medan Helvetia yang terdiri dari 7 orang dan Masyarakat yang terdiri dari 10 orang. Informan dalam penelitian ini terdiri dari tiga kategori, yaitu Camat beserta jajaran staff Kecamatan Medan Helvetia, Staf Administrasi Dinas Kependudukan dan
Pencatatan Sipil Kota Medan yang ditempatkan di Kantor Kecamatan Medan Helvetia dan Masyarakat.Dalam penyusunan pertanyaan wawancara, peneliti menggunakan tipe wawancara secara sistematis, dimana sebelum memulai wawancara terlebih dahulu peneliti menyusun daftar-daftar pertanyaan yang diajukan.

Dalam melaksanakan wawancara dengan informan, peneliti mengajukan pertanyaan-pertanyaan wawancara sesuai dengan permasalahan yang akan dibahas, yaitu Implementasi Good Governance Sebagai Upaya Pencegahan Penyakit Birokrasi Dalam Pelayanan Publik di Kantor Kecamatan Medan Helvetia. Peneliti juga menanyakan terhadap informan masyarakat untuk mengetahui bagaimana Implementasi Good Governance Sebagai Upaya Pencegahan Penyakit Birokrasi Dalam Pelayanan Publik khususnya dalam Bidang Tata Pemerintahan di Kecamatan Medan Helvetia dari sudut pandang dan pengalaman yang dirasakan oleh masyarakat pada saat berurusan dengan pelayanan publik dalam Bidang Tata Pemerintahan di Kecamatan Medan Helvetia.

\section{SIMPULAN}

Berdasarkan pemaparan hasil wawancara yang telah di deskripsikan pada bab sebelumnya maka dapat ditarik kesimpulan sebagai berikut:

1.) Untuk kualitas pelayanan administrasi kependudukan di Kantor Kecamatan Medan Helvetia sudah dijalankan dengan baik, dan

2.) Untuk kendala dan hambatan dalam pelayanan administrasi kependudukan di Kantor Kecamatan Medan Helvetia sebagian sudah diantisipasi dengan baik, walaupun ada beberapa kendala dan hambatan seperti minimnya partisipasi masyarakat, kurangnya SDM aparatur, serta minimnya dana dan infrastruktur jalan.

Berdasarkan dari hasil penelitian yang dilakukan oleh peneliti, sehubungan dengan Implementasi Good Governance 
dalam Pelayanan Publik di Kecamatan Medan Helvetia, peneliti akan memberikan beberapa masukan dan saran, yaitu:

1.) Dalam Implementasi diperlukan adanya semangat dan kreativitas serta inovasi setiap program, kerjasama yang baik dengan seluruh stakeholder dengan melibatkan para ahli di dibidangnya dengan bekerjasama dengan lembaga Perguruan Tinggi, Lembaga Riset, serta Pemerhati Kebijakan Pelayanan Publik di Kota Medan, dan

2.) Perlunya dioptimalkan Dana Kecamatan yang digelontorkan oleh Pemerintah Pusat secara efektif dan efisien agar program pelayanan publik dapat berjalan dengan baik.

\section{DAFTAR PUSTAKA}

A. G. Subarsono. 2005.Analisis Kebijakan Publik Konsep, Teori, dan Aplikasi. Yogyakarta: Pustaka Pelajar.

Albrow,

Martin.

1989.

Birokrasi.diterjemahkan oleh Rusli Karim dan Totok Daryanto. Yogyakarta: PT. Tiara Wacana.

Arikunto, Suharsimi. (2005).ManajemenPenelitian. Jakarta: RinekaCipta.

Bogdan, Robert dan Taylor.Pengantar Metode Penelitian Kualitatif, Terjemahan oleh Arief Rurchan, (Surabaya: Usaha Nasional, 1992).

Chandler, Ralph and C. Plano. 1988. The Public Administration Dictionary. New York ; John Wily and Sons Book.

Diahloka, Carmia. 2013. Membangun Kualitas Pelayanan Publik Melalui Peningkatan Etos Kerja
Pegawai.Malang; Jurnal Ilmu Administrasi Publik FISIP Universitas Tribhuwana Tungga Dewi.

Gunawan, Imam. 2014. Metode Penelitian Kualitatif : Teori dan Praktik. Jakarta: Bumi Aksara.

Kristiadi, J.B. 1993. Optimasi Sumber Daya Pembangunan Melalui Peningkatan Peran Swasta dalam Pembangunan Sektor Publik.Jakarta; Jurnal Ilmu Administrasi dan Organisasi FISIP Universitas Indonesia.

Osborne, David and Ted Gaebler. 1992.Reinventing Government ; How The Enter Preneural Spirit is Transforming the Public Sector. New York ; Penguin Book.

Patton, QM. 1997. Qualitative Ev aluation and Research Methods.CA sage Publications, Newbury Park.

Rinaldi, Rudi. 2012. Analisis Pelayanan Publik (Studi Sekretariat Daerah Propinsi Sumatera Utara).Medan; Jurnal Ilmu Administrasi Publik FISIP - Universitas Medan Area

Sugiyono. 2002. Metode Penelitian Administrasi. Bandung. CV Alfabeta.

William, David. (1997). Metode Penelitian Kebijakan Publik. (Samodra Wibawa, Penerjemah).Yogyakarta: Gajah Mada University Press.

Winarno, Budi. 2004. Teori dan Proses Kebijakan Publik. Yogyakarta: Media Pressindo. 